\title{
A revista Nin entre novos prazeres e novos conteúdos
}

\author{
Muriel Emídio Pessoa do Amaral ${ }^{1}$ \\ Bruna Neves Pellegrini2
}

Resumo

A partir do conceito de representação social desenvolvido por Denise Jodelet em interface às reflexões de Michel Foucault sobre sexualidade, este texto pretende discorrer sobre as representações de sexualidade, corpo e gênero apresentadas pela revista erótica Nin, naked for no reason. O periódico apresenta artigos, ensaios fotográficos e produções artísticas que pretendem reconfigurar as representações de corpo e desejo para além dos códigos previamente estabelecidos. A proposta da revista pretende oferecer outras práticas discursivas que dialoguem com intenções feministas e agir como contraponto às representações cristalizadas.

Palavras-chave: Revista Nin. Representação social. Corpo. Sexualidade

\section{Nin Magazine between new pleasures and new contents}

\section{Abstract}

From the concept of social representation developed by Denise Jodelet in interface with Michel Foucault's reflections on sexuality, this text intends to discuss the representation of sexuality, body and gender by erotic magazine Nin, naked for no reason. The magazine features articles, photographic essays and artistic productions that aim to reconfigure body and desire representations beyond previously established codes. The magazine's proposal intends to offer other discursive practices that dialogue with feminist and to act as a counterpoint to crystallized representations.

Keywords: Nin Magazine. Social representation. Body. Sexuality

\footnotetext{
1 Pós-doutorando em Jornalismo pela Universidade Estadual de Ponta Grossa (UEPG), mestre e doutor em Comunicação pela Universidade Estadual Paulista (Unesp/Bauru), Doutorado Sanduíche em Estudos Culturais pela Universidade de Aveiro, bolsista Capes.

2 Mestra em Comunicação Visual pela Universidade Estadual de Londrina (UEL), professora do Departamento de Jornalismo do Centro Universitário Metropolitano de Maringá (Unifamma).
}

Revista Pauta Geral-Estudos em Jornalismo, Ponta Grossa, vol. 6, n. 2, p. 90-107, Jul/Dez. 2019 


\section{REVISTA PAUTA GERAL}

\section{ESTUDOS EM JORNALISMO}

10.5212/RevistaPautaGeral.v.6.i2.0006

\section{Introdução}

Este artigo parte da percepção de que o corpo, o desejo e a sexualidade das mulheres são frequentemente explorados e vendidos para o consumo dos homens e da sociedade capitalista. No entanto, quando os corpos e a sexualidade das mulheres são explorados de outras maneiras, a favor de seus desejos, inclusive, dentro das práticas e lógicas do campo da comunicação e também do jornalismo, há outras possibilidades de representação deles. Como sintoma de atividades que vão para além da cristalização dos modos de representação, este texto pretende analisar a revista Nin, como veículo que opera para oferecer outras representações sobre corpo, sexualidade e prazer, principalmente acerca das questões femininas, misturando referências, identidades e manifestações de desejo e erotismo.

A revista pode ser considerada como expoente do movimento feminista contemporâneo, que é diverso e plural, pois, pede pela autonomia sobre o corpo das mulheres e pela liberdade de representações sobre os corpos, principalmente em mobilizações construídas dentro do espaço virtual, a formação de coletivos e a interseccionalidade, ou seja, a percepção da necessidade de afirmação das mulheres no espaço público e o ocorrência de outras demandas como o combate ao patriarcado e ao machismo e outras ações que promovem a invisibilidade e a disciplina e controle do corpos e subjetividade das mulheres (MATOS, 2010). Em sociedades disciplinares (FOUCAULT, 2017), discursos funcionam como um poder repressor sobre a individualidade; sendo esses discursos proliferados por diversos meios como, por exemplo, religião, família, escola e, também, os discursos jornalísticos e midiáticos, que também podem interferir sobre corpos e sexualidades femininos. A prática de controle e disciplina dos corpos pode ser reconhecida dentro das atividades do jornalismo, como apontou Gomes (2003), enquanto tecnologia de poder para formatar corpos, subjetividades e mentes. Este fenômeno acontece, por exemplo, em revistas sobre práticas de esporte, de dietas e revistas femininas que, segundo Buitoni (2009), esta qualidade de imprensa mais forma que informa, posicionamento que vai ao encontro das estratégias de disciplina e controle de corpos e subjetividades apresentados por Foucault. Em contrapartida a esta atuação, a revista Nin abre brechas nestas formas cristalizadas de representação para além dos signos estereotipados sobre a condição feminina. Nas 


\section{REVISTA PAUTA GERAL}

\section{ESTUDOS EM JORNALISMO}

10.5212/RevistaPautaGeral.v.6.i2.0006

páginas da revista, corpos masculinos dialogam livremente por corpos femininos de mulheres, de travestis e de transexuais; são pessoas maduras, com sobrepeso, peludas ou sem pelos que estampam os ensaios fotográficos e dividem espaços com artigos e entrevistas que oferecem visibilidade a outras sexualidades e desejos fora do esquadro heteronormativo.

Dessa forma, a partir do conceito de representação social desenvolvido por Jodelet (2001) em interface às reflexões sobre sexualidade apresentadas por Michel Foucault $(2017,2015,1984)$, este artigo tem por objetivo analisar a Revista Nin, uma publicação erótica criada por mulheres, que atua na contramão de discursos estereotipados sobre a sexualidade, principalmente de mulheres, a fim de compreender como o corpo e a sexualidade podem ser explorados em referenciais libertários, promovendo ações políticas para fora das representações cristalizadas sobre o corpo e subjetividade. Para isso, foram selecionadas as matérias/entrevistas das capas da revista, mais uma matéria acompanhada por um ensaio fotográfico escolhidos aleatoriamente em cada edição. Do universo composto, portanto, de 68 textos, foram analisados oito deles, selecionados por amostragem; sendo três da primeira edição, dois da segunda e três da terceira.

\section{Desenvolvimento}

A Nin é uma revista anual ${ }^{3}$, impressa e erótica. A publicação pertence à Editora Guarda-Chuva e é editada por Alice Galeffi e Letícia Gicovate. Galeffi é publisher e Gicovate é publicitária e editora de conteúdo. A revista é bilíngue, circula dentro e fora do Brasil, e possui colaboradores do mundo inteiro e, até 2019, conta com três edições publicadas que dissertam sobre sexualidade e erotismo, principalmente de mulheres, mas também de homens, travesti e transexuais. No site da publicação, onde também é disponibilizada uma versão limitada de cada edição da revista, pouco se diz sobre sua identidade, que parece não querer ser definida:

A Nin é uma revista impressa de arte erótica criada para aguçar os sentidos e desmitificar o erotismo através de imagens e palavras. Criada por duas mulheres, a Nin apresenta em suas edições bilíngues visões pessoais e amplas de colaboradores do mundo inteiro sobre o corpo, a

\footnotetext{
3 A revista não foi veiculada em 2017 e, até à conclusão deste artigo, a edição de 2019 também não foi publicada. Todavia, há conteúdos atualizados no site da publicação.

Revista Pauta Geral-Estudos em Jornalismo, Ponta Grossa, vol. 6, n. 2, p. 90-107, Jul/Dez. 2019
} 


\section{REVISTA PAUTA GERAL}

\section{ESTUDOS EM JORNALISMO}

10.5212/RevistaPautaGeral.v.6.i2.0006

nudez e a sexualidade, combinando elegância, humor, naturalidade e delicadeza. Para exibicionistas e voyeurs, para homens e mulheres, para você! (Site da Revista Nin, grifo deles ${ }^{4}$ ).

Pela citação é possível perceber que a Nin não pretende segmentar seu público por idade, sexo, gênero ou qualquer outra especificação. $O$ foco é se manter aberta e isso também pode ser observado em seu extenso leque de representações, pois, como afirma Neto e Amaral (2018, p. 10), a revista: "retrata homens e mulheres com sobrepeso, carecas, tatuados, peludos ou depilados, transexuais, homossexuais, lésbicas, exprofissionais do sexo que lutam para manter a vida fora desse nicho", ou seja, corpos que fogem das representações encontradas nas mídias convencionais - que contemplam mais o corpo jovem, belo e esculpido pela turgidez dos músculos.

A Nin se apresenta como uma revista erótica, mas afinal, o que é erotismo? Para este texto, o termo erótico e pornográfico não haverá distinção. Como reflexão apresentada por Leite Junior (2006), a distinção entre os conceitos foi devido às influências na categorização proposta por preceitos positivistas que foram travessados por questões moralizantes da ciência a partir do século VXIII. Ou seja, o erotismo estava associado a representações mais sutis sobre sexo e sexualidade, até porque o termo erotismo deriva do deus Eros, o deus do amor. Já o termo pornográfico refere-se às escritas das prostitutas, os relatos de suas experiências sejam em discurso oral ou memórias registradas em diários, o que poderia conotar aos olhos dos conversadores inferioridade nas representações e nas composições discursivas. É interessante lembrar também, como apresentou Foucault (2017), que a partir daquele momento, houve a hierarquização de corpos e subjetividades entre aqueles que seriam considerados "normais" ou "anormais", "saudáveis" ou "doentes" e outras dicotomias enquanto dispositivo de poder para classificação de sujeitos e grupos; e, dentro desta perspectiva, o pornográfico seria inferior devido à origem da sua produção, sendo como inferior aos olhos moralizantes. Assim, mesmo considerando que a Nin será denominada como uma publicação erótica, também pode ser pornográfica, sem qualquer perda de valor conceitual por justamente não hierarquizar conceitos e concepções ou reforçar preconceitos ao sexo e ou formas de representação.

Além disso, a Nin é uma revista feminista por trazer visibilidade aos desejos, principalmente de mulheres. Como aponta Gicovate, "antes de mais nada [Nin] é criada

${ }_{4}^{4}$ Disponível em <http://www.ninmagazine.com/sobre/> Acesso: 01 fev. 2018.

Revista Pauta Geral-Estudos em Jornalismo, Ponta Grossa, vol. 6, n. 2, p. 90-107, Jul/Dez. 2019 


\title{
REVISTA PAUTA GERAL
}

\section{ESTUDOS EM JORNALISMO}

10.5212/RevistaPautaGeral.v.6.i2.0006

por duas mulheres, que através do olhar, da curadoria, invertem a lógica estética e moral ao mostrar a mulher guiando o desejo". Gicovate também explica a pluralidade de representações apresentada na Nin, pois de acordo com ela:

\begin{abstract}
Sempre pensamos em ser uma revista inclusiva, a nossa ideia não era criar um clube visual sectário, pelo contrário, era ampliar o olhar sobre o erótico. E desde sempre nosso conceito de erotismo é guiado pelo olhar masculino, é ditado por desejos do homem. O corpo feminino nu não é uma novidade, a novidade é ter a nudez feminina através de uma curadoria feminina. É o nosso olhar, o nosso de desejo, de ver, ler, escrever e mostrar, do que ver e do que mostrar. Sem excluir o homem, pelo contrário, na Nin o homem hétero é confrontado com um outro homem nu, e tudo bem (GICOVATE, 2018, grifo dela) 5 .
\end{abstract}

A fluidez das identidades apresentadas pela revista oferece consistência de acreditar que essa seja queer, ou seja, as representações de identidade não estão colocadas em planos concretos a ponto de serem cristalizadas. A sexualidade, como aponta Butler (2003), é uma manifestação dotada de performatividade, isto é, não se apresenta de modo estanque, mas fruto da necessidade de reconfiguração e representações constantes, sem a necessidade de forjar estabilidade. O queer é performativo a partir do momento que, além de desafiar as representações identitárias marmorizadas, também oferece códigos libertários para outras representações represadas por uma questão de poder. Em outro estudo, Butler (2015) acredita que na ética e na formação da identidade contemporâneas, reconhecer-se a si mesmo pode ser uma manifestação de violência, uma vez que há a despossessão de si e muito mais uma relação normativa com o outro, propondo muito mais uma relação de norma que fruição. Por isso ela considera que "sou usada pela norma precisamente na medida em que a uso" (BUTLER, 2015, p. 51). Nenhum sujeito apresenta sua identidade e ética limitadas, uma vez que a linguagem que o compõe pode o afetar sob vários aspectos. A intenção de limitação da ética e da identidade tem como consequência a restrição dos sentidos, da própria subjetividade e do reconhecimento de si.

Não segmentar público pelo sexo a uma produção editorial descortina outra realidade para outras lógicas de produção de conteúdos, inclusive contemplando as produções jornalísticas que podem ser revistas sobre este prisma. Além disso, Nin não

\footnotetext{
5 Trecho da entrevista que Letícia Gicovate concedeu para colaborar com o desenvolvimento deste trabalho, em 03 de agosto de 2018.
}

Revista Pauta Geral-Estudos em Jornalismo, Ponta Grossa, vol. 6, n. 2, p. 90-107, Jul/Dez. 2019 


\section{REVISTA PAUTA GERAL}

\section{ESTUDOS EM JORNALISMO}

10.5212/RevistaPautaGeral.v.6.i2.0006

apresenta editorias fixas, índice ou elementos gráficos convencionais, a fluidez da produção poética e gráfica da publicação também é contemplada nas edições publicadas.

O nome da publicação é uma alusão à poetisa francesa Anaïs Nin, reconhecida por sua produção erótica e é tida como precursora das ideias libertárias sobre o sexo e a sexualidade da mulher. O subtítulo da revista: naked for no reason, significa nua sem motivo, algo que pode ser interpretado como um manifesto, possível de associação ao significado do corpo nu explorado na Marcha das Vadias, em que "a sensualidade dos corpos é celebrada; os padrões de beleza feminina são questionados por corpos que reivindicam, pelos diferentes formatos" (GOMES; SORJI, 2014, p. 49), e, além disso, confronta o pensamento de que o corpo feminino, quando nu ou parcialmente nu, se torna propriedade do homem. Assim, a frase nua sem motivo explora a ideia de que não existe necessariamente um motivo para que o corpo esteja nu e, principalmente, que não precisa estar relacionado ao desejo masculino, como comumente é aludido.

Pensando nisso e na possibilidade do corpo exposto na Nin servir como um meio de protesto político, Gicovate se pronuncia e afirma que apenas a exposição do corpo na Nin não significa um meio de protesto, mas sim "o fato da mulher ter o controle sobre seu desejo de mostrar ou não o seu corpo nu, de como mostrar, para quem mostrar, de ver outros corpos nus, de desejar", o que explica o Naked for no reason e confirma a interpretação a respeito da frase.

\section{Análises: sexualidade, gênero e representação}

Antes de adentramos às análises, é importante considerar como a sexualidade e o corpo foram alvos de interferência e tecnologias de controle e disciplina. Conforme apontado por Foucault (1984), a sexualidade é um dispositivo de poder, ou seja, analisando as movimentações históricas, percebeu-se que a presença da sexualidade hierarquizou, subjugou e descriminalizou sujeitos e grupos enquanto dignos de pertencerem ou não ao espaço público e político. E, por este motivo, a história da sexualidade humana apresenta passagens que evidenciam repressão e violência. Lembrando que para Foucault (1984), a repressão e o poder estão em toda parte, para estimular os sujeitos a agirem conforme os interesses hegemônicos na produção de sujeitos supostamente saudáveis, morais e produtivos, segundo a ordem capitalista.

Conforme apresentado por Foucault (1984), ainda na antiguidade grega, mulheres, crianças e estrangeiros não eram dignos de representação pública e política por não 


\section{REVISTA PAUTA GERAL}

\section{ESTUDOS EM JORNALISMO}

10.5212/RevistaPautaGeral.v.6.i2.0006

serem considerados cidadãos. No medievo, o corpo feminino era considerado impuro pela possibilidade de menstruação. Sob outra angulação, na modernidade e contemporaneidade, os corpos (masculino e feminino) eram alvos e também reproduziram os cânones de controle e disciplina na intenção de promover de políticas positivistas para a formação de uma sociedade supostamente saudável e produtiva economicamente.

Importante destacar que o desenvolvimento da repressão sexual está atrelado ao desenvolvimento do capitalismo. Afinal, segundo Foucault (2017), o controle sexual significa sua incompatibilidade com o trabalho e isso explica como a repressão moderna se sustenta, pois "na época em que se explora sistematicamente a força de trabalho, poder-se-ia tolerar que ela fosse dissipar-se nos prazeres, salvo naqueles reduzidos ao mínimo, que the permitem reproduzir-se?" (FOUCAULT, 2017, p.10). A partir disso, as atenções concentraram-se em controlar a sexualidade humana para que ela seja útil e politicamente produtiva associada aos valores produtivos, ou seja, a repressão sexual faz parte da ordem burguesa.

Em comunhão com os valores apresentados, há também a dominação masculina sobre os corpos e subjetividades femininos, esse poder atribuído aos homens e essa busca por dominação são abordados por Beauvoir (2016a), quando a filósofa diz que o prazer do homem no ato sexual não é apenas um prazer subjetivo, ele quer "conquistar, pegar, possuir; ter uma mulher é vencê-la; penetra nela como o arado nos sulcos da terra; ele a faz sua como faz seu chão que trabalha: ara, planta, semeia" (BEAUVOIR, 2016a, p. 214). Dessa forma, por muitos anos, o prazer da mulher foi negligenciado, pois a libido e o orgasmo eram forças de sentido viril, assim, aquelas que alcançavam o orgasmo eram consideradas "viriloides" (BEAUVOIR, 2016a, p. 68-69).

Entende-se que, ao longo dos anos, a sociedade patriarcal e ocidental passou a reconhecer mais abertamente o direito de o homem satisfazer seus desejos sexuais (tratando-se do homem heterossexual, encaixado nos padrões normalizadores), enquanto a mulher continuou sendo reprimida, ao passo que seu corpo é constantemente explorado a fim de servir como objeto de consumo e desejo. Estas práticas constituíram, mesmo que violentamente, representações sociais sobre a sexualidade e desejo das mulheres, limitando seus desejos aos desejos masculinos. E, mesmo havendo a tendência de cristalizar as representações de poder, há movimentos contrários para promover ações de resistência, como é o caso da revista Nin, que aborda outras representações de corpo e sexualidade e descortina as diversas formas de prazer.

Revista Pauta Geral-Estudos em Jornalismo, Ponta Grossa, vol. 6, n. 2, p. 90-107, Jul/Dez. 2019 


\section{REVISTA PAUTA GERAL}

\section{ESTUDOS EM JORNALISMO}

10.5212/RevistaPautaGeral.v.6.i2.0006

As representações sociais estão presentes em diversos meios, como nos discursos, nas palavras, nas mensagens que são veiculadas e, também, nas representações midiáticas. As representações, para Jodelet (2001), são concebidas em condutas e em organizações materiais e espaciais, ou seja, são sentidos que estão a par das movimentações sociais e históricas apresentadas em determinados recortes da história. Por este modo, as representações não podem ser compreendidas como manifestações do real, nem do ideal, mas o sintoma da relação entre o mundo, as coisas e as pessoas. As representações sociais são estratégias para interpretar e pensar a realidade. Além disso, é importante ressaltar que o sentido elaborado pelas representações sociais não é fruto de elaborações individuais, mas da potência de grupos e sociedades para promoção de sentidos.

Acredita-se que a noção de representação social vem do pensamento de que "a sociedade se exprimi simbolicamente em seus costumes e instituições através da linguagem, da arte da ciência, da religião, assim como através das regras familiares, das relações econômicas e políticas" (MAUSS 1979 apud MINAYO, 1995, p. 92). Partindo dessa perspectiva, se obtém a ideia de que as representações regem nossas relações com o mundo e com as pessoas, podendo funcionar como um meio de transformação social. Jodelet (2001) explica que representações são produções mentais, uma forma de conhecimento elaborada socialmente e partilhada entre a sociedade.

Como fenômenos cognitivos, envolvem a pertença social dos indivíduos com as implicações afetivas e normativas, com as interiorizações de experiências, práticas, modelos de condutas e pensamento, socialmente inculcados ou transmitidos pela comunicação social, que a ela estão ligados (JODELET, 2001, p. 22).

Importante ressaltar que o sujeito que constrói o discurso está inserido dentro de uma referência cultural e social, portanto, ele carrega marcas de sua subjetividade, como valores e ideologias. Sendo assim, a representação social é o código estabelecido para a composição desse discurso que é construído, como em uma determinada sociedade em que alguns códigos se tornam práticas a ponto de ganhar força de representação, servindo como uma simbolização social que interpreta um objeto (JODELET, 2001).

Da mesma forma que as representações sociais oferecem sentidos atribuídos ao mundo, isto não quer dizer que estes sejam imutáveis e constantes, mas podem ser fluídas e inconstantes. Como uma das estratégias para a formação das representações 


\section{REVISTA PAUTA GERAL}

\section{ESTUDOS EM JORNALISMO}

10.5212/RevistaPautaGeral.v.6.i2.0006

sociais estão os discursos e práticas midiáticas veiculadas no cinema, nos programas de TV, nas revistas e nos jornais, importantes espaços de circulação de cultura e símbolos que dialogam com as expressões culturais que estão em voga.

Por interferência das estratégias do capitalismo e da formação de alicerce de culturas estruturadas pelo patriarcado como estratégias de controle e disciplina do corpo, a representação dos corpos atende a discursos que tendem a cristalizar em signos que provocam prazer e fetichização, uma marca presente dentro do universo midiático, ainda mais sobre o corpo feminino. Além de estar a par das práticas de espetacularização, Debord (2003) e Haug (1997) mostram que os próprios sujeitos se tornaram mercadorias e, na sociedade capitalista, mercadorias são vendidas em razão de suas imagens - estas, objetos de fetichismo. Haug (1997) comenta que a sociedade capitalista exige corpos jovens, sem rugas, sem barriga, para que as pessoas se sintam insatisfeitas com a sua imagem e queiram comprar os produtos que prometem mudá-la, colocá-la no padrão estético difundido pela mídia enquanto representações supostamente de bem-estar, saúde e pertencimento social.

Em diálogo com estes pensamentos, Sibilia (2006) apresenta neste sentido a supremacia do corpo enquanto objeto de desejo e, por outro lado, o sintoma desta qualidade é o corpo que se torna dócil (empreendido no sentido desenvolvido por Foucault para controle e disciplina) pela interferência das tecnologias em associação às atividades da mídia e do mercado, ou seja, o corpo, mesmo dócil, "pode (e deve) ser aprimorado" (SIBILIA, 2006, p.113). Assim, Sibilia compara o corpo humano com imagens que precisam ser retocadas e até mesmo editadas em softwares de edição para fotografias digitais, de tal modo que aqueles que estão fora desse padrão almejado sejam rejeitados e excluídos da maior parte das representações midiáticas. Pensando nas mulheres:

\footnotetext{
Assim como em outros tempos o acúmulo de gordura no abdome das mulheres era apreciado como um sinal de abundância e fertilidade, os ventres lisos, secos e torneados das modelos de hoje evidenciam outras qualidades, repelindo os excessos da sociedade contemporânea mediante um trabalho disciplinado sobre as formas do corpo: "estoicismo, força de vontade, ambição e sorte". Além de encarnar esses valores mais próximos do ideal apolíneo que do dionisíaco, mais perto do ascetismo que do hedonismo -, tais corpos são desenhados, exibidos, copiados e consumidos como imagens (SIBILIA, 2006, p. 114 - 115).
}

Revista Pauta Geral-Estudos em Jornalismo, Ponta Grossa, vol. 6, n. 2, p. 90-107, Jul/Dez. 2019 
REVISTA PAUTA GERAL

\section{ESTUDOS EM JORNALISMO}

10.5212/RevistaPautaGeral.v.6.i2.0006

Além do corpo imaculado pelo tempo, as práticas e discursos midiáticos acerca dos desejos tendem a contemplar as representações patriarcais. Como exemplo de representação da sexualidade da mulher voltada ao homem é das coelhinhas da revista Playboy, sugeridas para agradar ao homem. A revista direcionada ao público masculino trata de "mulheres bonitas, sensuais, nuas e provocantes - recorrendo a um estereótipo consolidado socialmente, reduzindo a representação da mulher ao que ela deve ser e fazer para agradar um homem" (SILVA, 2003, p. 2017). Todavia, mesmo havendo estas práticas de representações, há também movimentos que vão contra a corrente predominante das representações cristalizadas sobre o corpo e subjetividade das mulheres. A Nin oferece outras propostas para além dos discursos e práticas previamente reconhecidos. Este movimento é possível porque há grupos que se articulam para a promoção de outros valores, ou seja:

O discurso de Nin oferece a intenção de desafiar, afrontar e subverter a ordem das leis previamente estabelecidas. Isso é política a partir do momento em que há a partilha de outros sentidos para além daqueles estabelecidos por alguma força de poder. Assim, a ação da revista é sintoma da necessidade de um tempo que não acabe mais a penumbra de uma condição subalterna (AMARAL, BERTOLLI, BAPTISTA, 2018, p. 295)

Pelas palavras dos autores, a Nin pode ser sintoma de representação social pela necessidade de reconfiguração de paradigmas para além das práticas previamente conhecidas, além de oferecer visibilidade a outras estratégias de representação e sentido aos corpos e desejos.

As práticas da revista Nin dialogam com representações do erotismo, mas não se encontram a par das representações cristalizadas sobre sexualidade e corpo. Na primeira edição da Nin, de 2015, no texto "Erotismo, sensualidade e sexualidade como potências para vida", o autor João da Mata aborda pensamentos de Wilhelm Reich e reflete sobre "a importância do exercício pleno da sexualidade como arma revolucionária, capaz de promover uma intensificação da vida" (MATA, 2015, p. 65). Ao longo do texto, João da Mata elenca os pensamentos de Reich acerca da psicanálise, sexualidade e poder, pois "segundo ele [Reich], a psicologia deveria caminhar junto com uma análise crítica das relações de poder, a fim de romper com práticas autoritárias presentes nas religiões, escolas e famílias, para então promover uma revolução social e sexual simultaneamente" 


\section{REVISTA PAUTA GERAL}

\section{ESTUDOS EM JORNALISMO}

10.5212/RevistaPautaGeral.v.6.i2.0006

(MATA, 2015, p. 65). É interessante reconhecer que o autor, sob outro prisma metodológico, a epistemologia da psicanálise, reconhece a sexualidade como prática de poder, assim como apontou Foucault ao discorrer sobre a história da sexualidade. Assim, o autor aborda a ideia de Reich sobre uma política sexual libertária e a importância de sociabilidades menos disciplinares:

A sexualidade é bem mais ampla que o ato sexual em si, e está envolvida com a própria vivência cotidiana do erotismo. A questão é que hoje não se distingue mais o erotismo propriamente dito e a pornografia, que é uma deturpação da noção pura do erotismo. Enquanto a experiência erótica está relacionada a tudo que diz respeito ao plano das sensações corporais, a pornografia alimentase das fantasias e imagens racionais (MATA, 2015, p. 65).

Para o autor do texto, o prazer não se encontra exclusivamente no ato sexual, mas também na potência que "emerge nas amizades, nas relações entre pais e filhos, na relação com o trabalho e a criação, enfim, nos inúmeros instantes que fazem da vida acontecimentos imanentes e afirmativos" (MATA, 2015, p. 65). Para além disso, degustar uma boa comida, escutar uma música ou contemplar uma obra de arte podem ser atos repletos de erotismo, uma vez que provocam sensações agradáveis ao corpo. Para ilustrar o texto, Lídia O, artista brasileira, apresenta autorretratos nua. Nenhuma novidade para uma revista erótica, entretanto, o que chama a atenção é a forma física de Lídia: corpulenta, ela tem a cabeça raspada e expõe sem pudor as marcas do corpo (celulite, flacidez, gordura localizada) aquilo que a sociedade disciplinar procura esconder ou aniquilar. Oferecer esta qualidade de representação e visibilidade também traz à tona referências políticas sobre o corpo e sexualidade enquanto potência feminista, uma vez que não escamoteia outras representações e evolui para além dos conteúdos eróticos que contemplam corpos lisos e túrgidos. 


\section{REVISTA PAUTA GERAL}

\section{ESTUDOS EM JORNALISMO}

10.5212/RevistaPautaGeral.v.6.i2.0006

Figura 1. Autorretratos Lídia $\mathrm{O}$

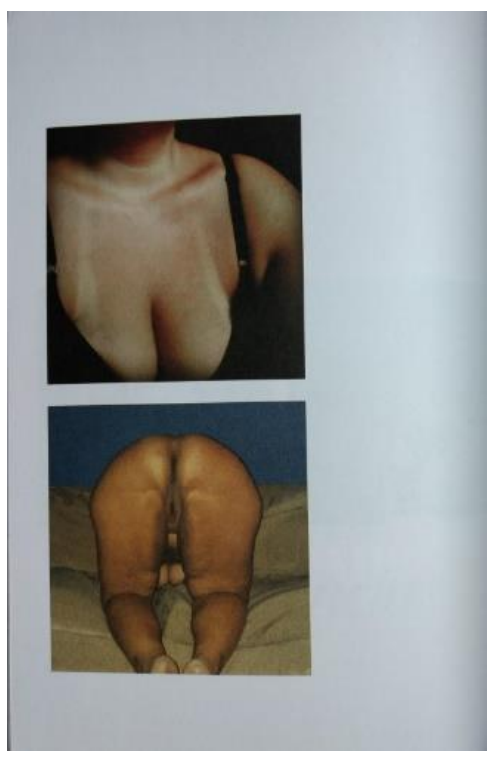

Fonte: Nin, vol I, p. 64
Figura 2. Autorretratos Lídia O.

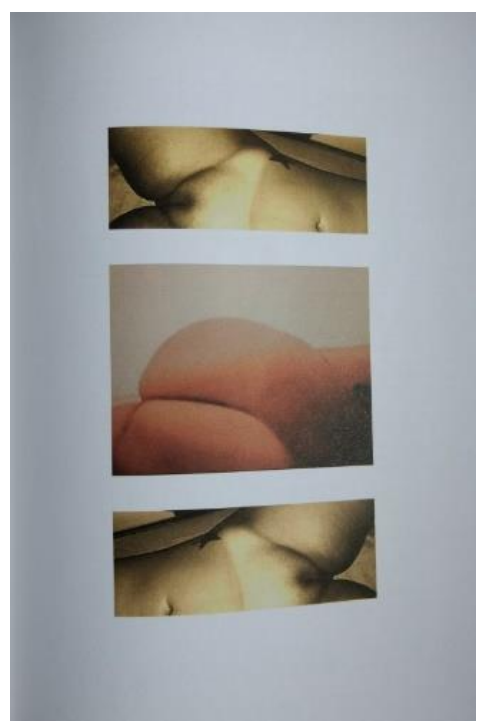

Fonte: Nin, vol I, p. 67.

Os conteúdos da Nin não se limitam apenas à exposição do corpo, mas também em refletir sobre as variantes e potencialidades do desejo e enfretamento de estereótipos. Enquanto representações imagéticas, o ensaio de Lídia $O$. foge do padrão estigmatizado e mostra seu corpo sem pudor. Sua ousadia balança com as estruturas do poder e tornase resistência, como aponta Foucault (2015), um caminho para desvendar outras formas de representações para além daquelas conhecidas nas práticas da comunicação midiática.

Nesta mesma edição, a revista veiculou uma entrevista com llona Staller, nome da ex-atriz pornô Cicciolina. Durante a entrevista, ela relatou experiências ainda no universo artístico e os problemas enfrentados por mulheres fora e dentro das filmagens das produções eróticas. De acordo com ela, que também já foi deputada na Itália, há a necessidade de empoderamento feminino para que as mulheres sejam reconhecidas politicamente no espaço público. Além disso, ela reconhece que as produções eróticas podem exercer essa função desde que sejam levadas em consideração as relações de prazer e desejo femininos. Na entrevista, a Nin mostra a pluralidade de Staller como mulher e sua possibilidade de ser mais do que uma única faceta associada às produções eróticas cinematográficas. Limitar os modos de representação a códigos fechados, de 


\section{REVISTA PAUTA GERAL}

\section{ESTUDOS EM JORNALISMO}

10.5212/RevistaPautaGeral.v.6.i2.0006

acordo com Burke (2004), reforça estereótipos e, por consequência, pode ser um sinal de violência simbólica.

Ainda nesta edição, Ronaldo Lemos aborda no texto "Sexo \& desigualdade" reflexões sobre o funk como alternativa e como possibilidade libertária para a sexualidade feminina. O artigo aponta os enfrentamentos de sujeitos LGBTQI+s (lésbicas, gays, bissexuais, transgêneros, queers e intersexuais, etc...) em diálogo com a ação libertária sugerida por Donna Haraway pelo ensaio Manifesto ciborgue. Para a autora, assim como para Lemos, o ciborgue é um expoente da liberdade ao superar as amarras das identidades marmorizadas por oferecer uma revisão sobre o conceito de gênero ao desvencilhar-se de estratégias patriarcais.

As concepções ciborgues também podem ser consideradas como ações no campo do feminismo porque transcende dualidades (homem $x$ mulher, hétero $x$ homo, macho $x$ fêmea, orgânico $x$ artificial, etc.) e, dentro desta seara, as qualidades ciborgues podem ser interpretadas como exemplos de manifestações libertárias e convocam para reflexões sobre reconsiderar o papel de referências patriarcais e conservadoras, uma vez que os signos cristalizados sobre estes temas perdem o sentido pela reconfiguração moral contemporânea.

A segunda edição de Nin trouxe na capa a imagem do ensaio fotográfico e entrevista com a modelo transexual Camila Ribeiro, o que contribui para reiterar a estética queer da publicação. Sendo uma modelo transexual, a revista abre a ideia de visibilidade aos corpos LGBTQI+, e mostra outras representações de corpos e subjetividades para além dos discursos e práticas previamente estereotipados dentro das representações do jornalismo e da comunicação sobre corpos femininos e corpos de travestis e transexuais não fetichizados.

Na mesma edição, a revista também veiculou um artigo e parte dos trabalhos de Aleta Valente. Artista e performer carioca, Aleta dá vida ao avatar criado por ela mesma, Ex-miss-Febem, perfil que mantém em suas contas nas redes sociais, sendo autora de muitas das próprias aparições. Evidenciando o corpo, algumas vezes nu, e as condições de Bangu, subúrbio carioca onde mora, Aleta realiza performances que reconsideram as representações do corpo feminino de modo libertário, longe das tecnologias de controle e disciplina, expondo os seios, pelos e menstruação.

Nas obras de Aleta são trazidos à tona a aridez e adversidades encontradas no subúrbio e a exposição do corpo como protesto, temas nem sempre aceitos dentro das Revista Pauta Geral-Estudos em Jornalismo, Ponta Grossa, vol. 6, n. 2, p. 90-107, Jul/Dez. 2019 


\section{REVISTA PAUTA GERAL}

\section{ESTUDOS EM JORNALISMO}

10.5212/RevistaPautaGeral.v.6.i2.0006

práticas das artes e das formas de representação do erotismo nas práticas do jornalismo. No texto em que apresenta a artista, Alice Colassanti considera que as obras e a atuação de Aleta podem ser consideradas feministas por libertar o corpo e as subjetividades femininos:

(...) com fins de protesto, uma performance cotidiana com fins de crítica social, uma performance em processo que confronta as normas culturais vigentes, com vistas a uma transformação da realidade, a libertação do corpo da mulher, a dissolução da ideologia machista dominante e o fim das minorias (...). (COLASSANTI, 2016, p. 63).

As obras e instalações de Aleta perpassam a necessidade de libertar o corpo das amarras que ainda insistem em agir sobre o corpo das mulheres e, por isso, por ser considerada uma manifestação de feminismo contemporâneo. Como apresenta Colassanti (2016), há uma série de ações que privam as mulheres de liberdade e da possibilidade de prazer como a mutilação clitoriana e o número de feminicídio que ocorre no Brasil (de acordo com ela, a cada uma hora e meia, uma mulher é morta por um homem). Como uma prática de liberdade, como Colassanti aponta “(...) ingressamos na Idade do Deixa Ela em Paz. Ela quem? Ela, a vulva, a vagina, a buceta. Ela, a boca do mundo (COLASSANTI, 2016, p. 62)", Aleta fotografa a própria vagina repleta de sangue de menstrual e a intitula "L'origine du noveau monde", uma sátira à obra "A origem do mundo", de Gustave Coubert, em que uma vagina despida é retratada. Oferecer outra releitura da obra e das representações abre espaços para outros sentidos não apenas dos corpos, mas dos sentidos dos corpos e subjetividades, “(...) é preciso ler Aleta dentro do campo das manifestações simbólicas. É esse o território de onde seu discurso é emitido" (COLASSANTI, 2016, p. 62). Pelas reflexões apresentadas, o conteúdo da matéria e do ensaio mostram a necessidade de transgressão dos modos de representação, tanto da arte, como dos modos de representação dos corpos e dos conteúdos editoriais.

A terceira edição da revista traz ensaio fotográfico com a atriz Débora Nascimento, em poses sensuais, ela posa à publicação grávida de oito meses, uma ode à sexualidade feminina em nome do desejo, refutando considerações entre sagrado e o profano e refletindo sobre outras considerações acerca de maternidade e gênero. Por meio deste ensaio, a Nin mostra a gravidez com um estado natural e sagrado do corpo da mulher, mas não trata disso de forma romantizada, pois Débora, a "modelo escolhida" para o ensaio, toca em assuntos como feminismo, pressão do patriarcado, liberdade e 


\section{REVISTA PAUTA GERAL}

\section{ESTUDOS EM JORNALISMO}

10.5212/RevistaPautaGeral.v.6.i2.0006

sexualidade, demonstrando resistência a ideia romântica da gravidez que foi perpetuada socialmente.

Ainda na intenção de refletir sobre a dicotomia entre o sagrado e o profano nas representações da sexualidade, a edição trouxe uma entrevista com o rabino Nilton Bonder. Para abordar essa relação, o rabino relatou sobre a figura de Lilith, figura mitológica que, supostamente, seria a primeira mulher do mundo. Lilith não teve o mesmo destaque de Eva nas estórias bíblicas por ser insubordinada e, por isso, o surgimento de outra figura que fosse mais afável aos dogmas religiosos e, consequentemente, submissa à força do homem. Pelas reflexões do rabino, coube à Eva representar a figura feminina na sociedade enquanto uma entidade desprovida "fragilizada pela sua própria potência, sendo amputada de sua liberdade, de seus desejos, da força dos seus instintos e de sua sexualidade" (GICOVATE, 2018, p. 78). Pelas palavras de Nin, a mulher, até mesmo nas gêneses da humanidade pelo viés bíblico, é elencada como uma figura que sofre pelo silenciamento de visibilidade pública, além de ter seus desejos e subjetividades negligenciados pelas estruturas e discursos de poder.

$\mathrm{Na}$ mesma edição, a artista plástica inglesa Sarah Maple apresenta reflexões sobre a possibilidade de manifestações feministas em países muçulmanos. Em tom de deboche e ironia, ela apresenta em uma tela a repulsa da sociedade ao ver uma mulher de vestido branco exibindo as manchas da menstruação. Dividindo espaço com os manifestos feministas de Sarah, o fotógrafo Alessandro Panelli descortina o corpo masculino em imagens de corpos nus em cenas de desfrute.

Alguns dos ensaios abordados na Nin também podem ser relacionados ao conceito de abjeção abordado por Butler (2017), ao tratar do queer. O "abjeto" é compreendido como algo ou alguém pelo qual se sente horror ou repulsa. Assim, acreditase que a menstruação, transsexuais e corpos que estão ao oposto do que é ditado como belo, saudável pelas sociedades disciplinares podem ser vistos como abjetos. Oferecer outros caminhos para contemplar outras manifestações de sexualidades e desejos também podem ser considerados atos políticos, uma vez que esta prática de jornalismo recorre à oferta de visibilidade e reconhecimento público de sujeitos e grupos que se encontram às margens sociais por uma questão de poder. Para além dos códigos que cristalizam e limitam as expressões de representações sobre gênero e sexualidade, provenientes das práticas do jornalismo e da comunicação enquanto atuações de poder, 


\section{REVISTA PAUTA GERAL}

\section{ESTUDOS EM JORNALISMO}

10.5212/RevistaPautaGeral.v.6.i2.0006

poderá haver também outros códigos que não visam a tomada de poder, mas a melhor equalização deste poder a outras representações de sexualidade e desejo.

\section{Considerações finais}

Mesmo reconhecendo o vigor de formas de representação cristalizadas sobre o desejo, sexualidade e prazer, principalmente de mulheres e do gênero feminino, nas práticas do jornalismo, há caminhos que podem ser traçados para além das representações construídas sob alicerces estigmatizados. A revista Nin oferece visibilidade e reconhecimento político e público a outras expressões da sexualidade e desejo, além de abrir espaços para outras manifestações feministas para além daquelas consagradas. Obviamente que por ser uma publicação bilíngue, apresentar público restrito quanto ao interesse editorial e ser comercializada em espaços limitados favorecem a intenção de ruptura com a ordem disciplinar dos corpos e subjetividades, entretanto, ainda pode ser considerada um canal para outras representações sejam contempladas no espaço público.

É importante também considerar que as práticas do jornalismo não se encontram apenas no exercício canônico da profissão e da produção de conteúdos. Nin também subverte a prática tradicional de produção jornalística quando veicula em suas páginas entrevistas e artigos associados ao erotismo e divulgação científica. Para além disso, contemplar outras representações de desejo e do corpo também contribui de modo significativo para o fomento de movimentações contra hegemônicas e para o exercício de reflexão sobre os conteúdos midiáticos e as práticas do jornalismo e contribuir de modo significativo com práticas feministas. Abrir espaço para representações fora dos esquadros de poder é contemplar ações políticas pelas práticas de fazer jornalismo.

\section{Referências bibliográficas}

AMARAL, Muriel; BERTOLLI FILHO, Claudio, BAPTISTA, Maria Manoel. A perversão como estética política para a sexualidade: notas sobre a revista Nin. Brasiliana - Journal for Brazilian Studies, v.6, n.1, p. 280-298, 2017.

BEAUVOIR, Simone de. O segundo sexo: fatos e mitos, vol 1, - 3.ed. Rio de Janeiro: Nova Fronteira, 2016.

BEAUVOIR, Simone de. O segundo sexo: a experiência vivida, vol 2, - 3.ed. Rio de Janeiro: Nova Fronteira, 2016. 


\section{REVISTA PAUTA GERAL}

\section{ESTUDOS EM JORNALISMO}

10.5212/RevistaPautaGeral.v.6.i2.0006

BUITONI, Dulcilia. Mulher de papel: a representação da mulher pela imprensa feminina

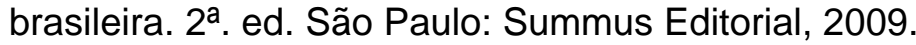

BURKE, Peter. Testemunha ocular. Bauru: EDUSC, 2004.

BUTLER, Judith P. Problemas de gênero: feminismo e subversão da identidade. - $15^{\text {a }}$ ed. - Rio de Janeiro: Civilização Brasileira, 2017.

COLASSANTI, Alessandra. Aleta Valente, a boca do novo mundo. Revista Nin, v.1, n. 1, 2017, p. 62-63.

DEBORD, Guy. A sociedade do espetáculo. Ilha do Mel: Terra Vista. 2003. Disponível em <https://www.marxists.org/portugues/debord/1967/11/sociedade.pdf>. Acesso em 23 mai 2018.

FOUCAULT, Michel. História da Sexualidade 1: a vontade de saber. 4 ed. Rio de Janeiro/ São Paulo: Paz e Terra, 2017.

FOUCAULT, Michel. História da sexualidade 2: o uso dos prazeres. Rio de Janeiro: Edições Graal, 1984.

FOUCAULT, Michel. Microfísica do Poder. 3ªe ed. Rio de Janeiro: Paz e Terra, 2015.

GICOVATE, Letícia. Entrevista concedida à autora por e-mail. 3 ago. 2018.

GICOVATE, Letícia. Entrevista com Nilton Bonder. Revista Nin, p. 76-87, 2018.

GOMES, Mayra R. Poder no Jornalismo. 1. ed. São Paulo: Hacker e Edusp, 2003.

HAUG, Wolfgang Fritz. Crítica da estética da mercadoria. São Paulo: Fundação Editora UNESP, 1997.

JODELET, Denise. As representações sociais. Rio de Janeiro: Universidade do Estado do Rio de Janeiro, 2001.

LEITE NETO, Jorge. Das maravilhas e prodígios sexuais: a pornografia "bizarra" como entretenimento. São Paulo: Annablume, 2006.

MATOS, Marlise. Movimento e teoria feminista: é possível reconstruir a teoria feminista a partir do Sul global? Rev. Sociol. Polit., Curitiba, v. 18, n. 36, p. 67-92, 2010.

MINAYO, Maria Cecília de Souza. O conceito de representações sociais dentro da Sociologia clássica. In: GUARESCHI, Pedrinho; JOVCHELOVITCH, Sandra. Textos em representações sociais. 2. ed. Rio de Janeiro: Vozes, 1995, p.89 - 111.

NETO, José Miguel Arias; AMARAL, Muriel Emídio Pessoa do. A montagem perversa positiva da revista Nin. Porto Alegre: Revista Famecos, v. 25, n. 1, 2018. Disponível em: <http://revistaseletronicas.pucrs.br/ojs/index.php/revistafamecos/article/view/26869/0>. Acesso: 02 fev. 2018.

Revista Pauta Geral-Estudos em Jornalismo, Ponta Grossa, vol. 6, n. 2, p. 90-107, Jul/Dez. 2019 


\section{REVISTA PAUTA GERAL}

\section{ESTUDOS EM JORNALISMO}

10.5212/RevistaPautaGeral.v.6.i2.0006

SANTAELLA, Lucia. Corpo e comunicação: sintoma da cultura. 2. ed. São Paulo:

Paulus, 2006.

SIBILIA, Paula. A desmaterialização do corpo: da alma (analógica) à informação (digital). São Paulo: Comunicação, mídia e consumo. v. 3, p. 105 - 119, 2006.

Recebido em: 05/10/2019

Aprovado em: 25/10/2019

Revista Pauta Gerall-Estudos em Jornalismo, Ponta Grossa, vol. 6, n. 2, p. 90-107, Jul/Dez. 2019 